\title{
Reasons for wind turbine generator failures: a multi-criteria approach for sustainable power production
}

\author{
Rajakumar D. Gowdar ${ }^{* *}$ and M. C. Mallikarjune Gowda²
}

\begin{abstract}
Power generation quantity from wind sector is increasing at much faster rate day by day in the scenario of power systems, which obviously needs reliable operation. Therefore, accurate monitoring and error diagnosis are almost mandatory. This paper aims to identify important errors that affect the performance and can easily detect the faults of wind turbine generators (WTGs). Wind turbines are subjected to different sort of failures; thus, before starting to identify various kinds of errors, it is necessary to identify what kind of failures can be found in the real world which causes healthy operation of WTGs. Out of different errors, error that is caused by the operation of gearbox could stop or reduce the generation of power from WTGs for a long time. Recently, several condition monitoring and fault diagnosis techniques have been introduced in order to minimize downtime and maintenance cost while increasing energy availability and life time service of the wind farms. Different types of sensors have been used for long time in wind turbine fault diagnosis or monitoring systems to collect data of the generator health. Many researchers analyzed wind turbine failures using different software. The present study uses different approaches and prepares a multicriteria decision-making framework using analytic hierarchy process (AHP). The analysis of the data under AHP frame work revealed overspeed guard/turbine out of control error got the top most impediment to the healthy operation of WTGs, and high brake temperature fits in the fifth position among the five different error groups considered.
\end{abstract}

Keywords: Sustainable power production, Wind turbine generator, Multi-criteria approach,

Analytic hierarchy process

\section{Background}

Sustainable economic development is closely linked with the energy availability. Most of the world's commercial energy needs are met by fossil fuels coupled with negative environmental effects. To combat global warming and other environmental problems associated with these fossil fuels, many countries, including India, are increasingly adopting renewable energy sources. Such energy sources generally depend on energy flows through the earth's ecosystem from the insolation of the sun and the geothermal energy of the earth. Renewable energy sources can meet many times the present world energy demand, as

\footnotetext{
*Correspondence: rajakumardyl@gmail.com

${ }^{1}$ Department of Mechanical Engineering, GM Institute of Technology, P.B.

Road, Davangere, Karnataka 577006, India

Full list of author information is available at the end of the article
}

their potential is enormous. They can enhance diversity in energy supply markets, secure long-term sustainable energy supplies and reduce local and global atmospheric emissions (REN21 2010). They can also provide commercially attractive options to meet specific needs of energy services (particularly in developing countries and rural areas), and create new employment opportunities. Renewable energy produced from sustainable natural sources will contribute to sustainable development. They offer a promising alternative and/or supplement to traditional energy sources in developing countries. Among the different renewable energy sources, wind energy is making a significant contribution to the grid power installed capacity in India and is emerging as one of the competing options to mitigate pollution. Because wind energy is renewable and environmental friendly, systems that convert wind energy to electricity have developed rapidly.

\section{Springer}


However, the implementation of wind energy faces some barriers in reality.

The objective of the current study is to identify the errors that affect the healthy operation of WTGs and prepare a multi-criteria decision-making framework using AHP to prioritize them. Study considers five major wind potential sites with different geographical locations, different WTG manufacturers and different WTG rating capacities. However, healthy operation of the WTGs faces several errors acting in the field. Prioritization of these errors has to necessarily involve the multiple criteria. The perceptions and experiences of stakeholders are duly incorporated in this prioritization scheme, since they are the key persons of any initiatives for any initiatives to upgrade or replace the components of WTGs for healthy operation. In addition, such a prioritization process must also adopt multiple criteria such as impact of error removal on turbine performance, financial difficulty in error removal and impact of error removal on techno-economic performance. This paper comprises all these aspects comprehensively in ranking the errors in the selected wind farm.

There are a few studies in the area of renewable energy using multiple criteria to analyze various aspects of interest Hahn in his study on Reliability of Wind Turbines. It is clear that the failure rates of the wind turbines (WTs) now installed have almost continually declined in the first operational years. This is true for the older turbines under $500 \mathrm{~kW}$ and for the 500/600 kW class. However, the group of megawatt WTs show a significantly higher failure rate, which also declines by increasing age. But, including now more and more megawatt WT models of the newest generation, the failure rate in the first year of operation is being reduced. Fleming (2011) opines that we describe our exploration of existing wind turbine supervisory control and data acquisition (SCADA) data for development of fault detection and diagnostic techniques. Our ultimate goal is to be able to use SCADArecorded data to provide advance warning of failures or performance issues. For the work described here, we used data from the controls advanced research turbine (CART) at the National Wind Technology Center (NWTC) at the National Renewable Energy Laboratory (NREL). A number of measurements from the turbine are used to develop anomaly detection algorithms. Classification techniques such as clustering and principal components analysis were investigated.

Among the challenges, noted in the Department of Energy issued report "20 \% Wind Energy by 2030" (EERE 2030), are improvement in wind turbine performance and reduction in operating and maintenance costs. After the capital costs of commissioning wind turbine generators, the biggest costs are operations, maintenance and insurance (Zaheer et al. 2009; Musial 2007). Reducing maintenance and operating costs can considerably reduce the payback period and provide the impetus for investment and widespread acceptance of this clean energy source. Traditionally, condition monitoring systems for wind turbines have focused on the detection of failures in the main bearing, generator and gearbox, some of the highest cost components on a wind turbine (Crabtree 2010; Sheng et al. 2009; Wiggelinkhuizen et al. 2008).

According to Lin et al. (2016), their study considers three primary configurations and failure statistic analysis of wind turbines in China. This paper summarizes the failures of wind turbine components, such as frequency converters, generators, gearboxes, pitch systems, yaw systems, blades, braking systems and sub-synchronous machines. Although there are many failure types and various causes, we can deduce four primary reasons for these failures: lack of core technologies; inferior quality due to price competition; design standards and wind farm climate differences; and no mandatory quality certification and exterior factors, such as wind farm construction, power grids and maintenance. Finally, while aiming to improve the reliability, a reliability management method with regard to the design, manufacturing and maintenance of wind turbines was proposed.

Wind turbine failures are equivalent to crucial financial losses. Therefore, creating and applying strategies that improve the reliability of their components is important for a successful implementation of such systems. Two widely used methods are vibration analysis and oil monitoring. These are standalone systems that require installation of sensors and hardware. A supervisory control and data acquisition (SCADA) data-based condition monitoring system uses data already being collected at the wind turbine controller and is a cost-effective way to monitor for early warning of failures and performance issues. The paper also deals with the manipulation of a different kind of data coming from wind turbines: data obtained by the SCADA systems installed in many wind farms nowadays. They contain measurements of various variables, such as wind speed, bearing and oil temperatures, voltage and the power produced. The recordings of these systems are constant and available for every wind turbine in a farm, so they could be potentially used to monitor wind farms. Therefore, exploitation of these measurements that could lead to an effective online structural health monitoring (SHM) plan seems to be an attractive opportunity (Yang et al. 2013).

In addition, because of the availability of such data for every individual wind turbine, one could explore novel approaches in the SHM field by treating the whole farm as a population. Exploring the potential of a populationbased approach to damaging detection in this case could 
refer to adopting strategies that can determine the condition of a wind turbine according to the measurements obtained from other wind turbines in the farm.

In Papatheou et al. (2015), the potential of using SCADA data for the condition monitoring of wind turbines was explored. The power curve of each individual wind turbine in a wind farm is produced by a machine learning method using the SCADA data collected from the wind turbine. The constructed power curve of each wind turbine is then used to predict the power curves of other wind turbines. The residual error between the actual and predicted power produced was then used for the condition monitoring of wind turbines. The condition monitoring, fault diagnosis and reliability of major wind turbine components and sub-systems, such as blades (Yang et al. 2015), drive trains (Yang et al. 2015), power converters (Zhou et al. 2015), gearboxes (Yoon et al. 2015; Du et al. 2015) and bearings (Ming et al. 2015; Gerber et al. 2015), were well covered by the selected contributions. Moreover, it also uses sensors/signals for wind turbines fault diagnosis such as strain sensors (Yang et al. 2015; Yoon et al. 2015), vibration (Yang et al. 2015a, b; Du et al. 2015; Gerber et al. 2015), acoustic emission (Ming et al. 2015) and SCADA data (Long et al.; Papatheou et al. 2015).

In view of this, the present study uses the SCADA system for collecting the data which the study finds the best possible option for identifying the very important errors (study identifies five important errors) out of many which helps in maintaining the health of WTGs in a very good condition. It also resolves supervisory control tasks by automatically starting, stopping and resetting the turbines in case of errors/fluctuations. SCADA data-based health monitoring system is considered to be a cheaper solution than conditional monitoring system (CMS) (Antoniadou et al. 2015). In this paper, we describe our exploration of existing wind turbine SCADA data for development of error detection and diagnostic techniques using a multi-criteria approach to prioritizing them. Since the present error prioritization problem involves multiple criteria and qualitative value judgments for their measurement, it is felt that the AHP is the right tool for application.

\section{Analytic hierarchy process (AHP) frame work}

AHP was first developed by Thomas Saaty in the 1970s. The main purpose of AHP was to develop a theory and provide a methodology for modeling the unstructured problems in the economic, technical, social and management sciences (Saaty 1996). AHP not only supports decision makers by enabling them to structure complexity and exercise judgment, but allows them to incorporate both objective and subjective considerations in the decision process (Forman 1990). It is a powerful and flexible weighed scoring decision-making process to help people set priorities and make the best decision when both qualitative and quantitative aspects of a decision need to be considered.

\section{Analysis of error with AHP frame work}

Utilizing existing literature pertaining to the errors to WET and further discussion with experts in the field of wind energy and energy management, an error analysis frame work is developed as depicted in Fig. 1. Five groups of errors and four important criteria are considered relevant to the healthy operation of WET in any wind farm. As the analysis is to be carried out using the AHP, the frame work is prepared in the hierarchical structure as illustrated in the figure. The key dimensions under each of the error groups are also indicated. The frame work has three levels comprising the goal, criteria and errors (alternatives). Since the study frame work is based on a MCDM model, the error groups (which are to be prioritized based on multiple criteria) constitute the decision alternatives. The five errors categories covered by the study and the various dimensions used in their assessment are briefly discussed below in the context of WETs.

\section{Over speed sensor failure error (OSFE)}

This error is of particular relevance to almost all the different rating WTGs considering the safety and healthy operation of WTGs across any geographical location. In this study, the malfunctioning assessment of overspeed sensor failure is proposed to be done using the stake holder's opinions. For a more convenient opinion collection process, a pairwise comparison matrix will be utilized. This includes preparing a sequence of questions including instructions and a description of the goal of the study. A few of the dimensions that affect this type of error include malfunctioning or difference in revolution per minute (RPM) between wind turbine rotor and generator.

Further, during field survey it was observed that inefficient maintenance of the sensors and adoption of lowquality sensors leads to malfunctioning which in turn affects the operation of WTGs. Moreover, OSFE is considered to prevent other errors from being overcome. Lack of skilled or untrained operator may also lead to the reliable operation of the WTGs.

\section{Temperature measurement module failure error (TMFE)}

This error is significant in the context of geographical locations in view of the different temperature which influences the operating temperature of the turbines. If 


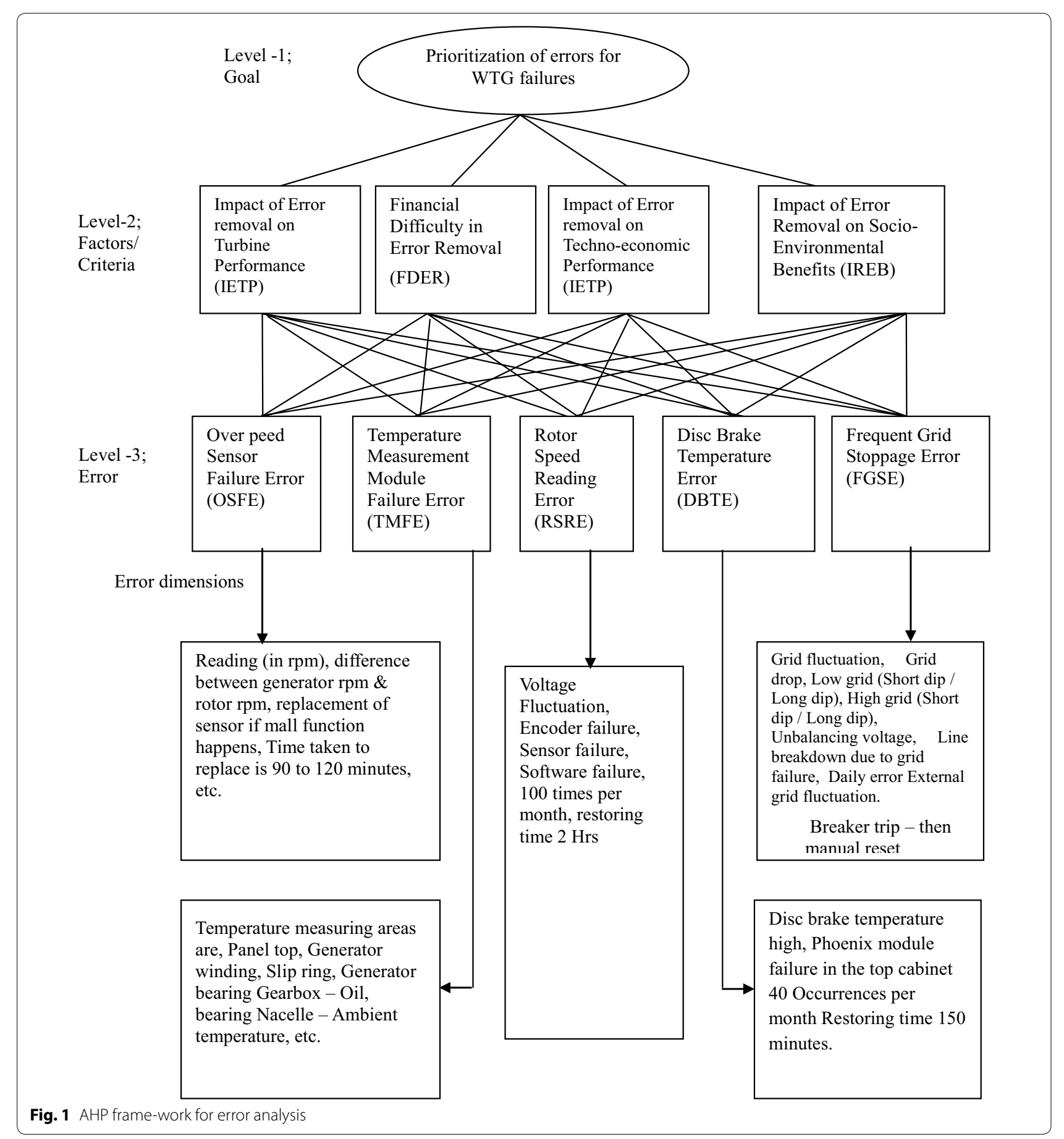

the temperature of the atmosphere varies rapidly due to continuous operation of WTGs, gearbox oil may decrease its life which affects the performance of turbines. If the temperature inside the nacelle varies, then various components such as slip ring and yaw bearing get affected. It is very much necessary to replace the sensor at the earliest to maintain the safe working temperature.

\section{Rotor speed reading error (RSRE)}

Despite major technological improvements that have been achieved, the intermittent nature of wind power generation remains a hindrance in the adoption of technology. This error is because of many parameters that happen to be at wind turbine rotor and generator. Variation in voltage fluctuation or variation in speed between 
high-speed shaft and low-speed shaft varies the rotation of wind turbines. Other parameters such as encoder failure, sensor failure and software failure also affect the performance of WTGs.

\section{Disk brake temperature error (DBTE)}

This error plays an important role while operating the WTGs under fluctuating wind conditions. When sudden changes in wind direction happen (like gusty winds), it leads to erratic rotation of wind turbines which may affect the sensor that is located near the disk. This error occurs where maximum variation of wind fluctuation occurs.

\section{Frequent grid stoppage error (FGSE)}

This error is not controlled by the wind farm people; it is purely controlled by the government power receiving and distributing persons. This also happens when there is high wind season/voltage variation in the grid/line breakdown due to grid failure, etc. This error may occur because of breakdown/maintenance/replacement of components in the power receiving station under either breakdown maintenance or regular maintenance.

The objective of the current paper is to prioritize aforesaid five error groups in the selected wind farms based on the following four criteria:

a. Impact of error removal on turbine performance (IETP): A hindrance for potential investors in wind energy is constituted by the economics of wind technology. It was observed that the failure rates of the WTGs now installed have almost continually declined in the first operational years. This is true for the age old turbines (under 500/600 kW class). However, the group of megawatt (MW) WTGs show a significantly higher failure rate, which also declines by increasing age.

But, including now more and more megawatt WTG models of the newest generation, and improved version of the wind turbines like gearless generators for higher capacity wind turbines, failure rate in the first year of operation is being reduced. Higher barrier intensity is likely to pose a bigger challenge to the wind farm clusters for an efficient method of harnessing power from wind. Though it is impractical to achieve the impact of removing all errors related to turbine technology adoption for better performance, an attempt is to be made toward reducing the errors to as low a value as possible. The impact of each of the five error groups is likely to differ in view of their relevance and context.

b. Financial difficulty in error removal (FDER): The financial resources required to eliminate/reduce the error is another important criterion in barrier ranking. Financial difficulty may be in the form of huge capital investment, cost of importing the components, cost of repairing/replacing the components, lack of technological up gradation, tax cost, etc. The financial errors are accompanied by economic obstacles given by uncertainties on purchase contracts. An owner of a particular rating wind turbine can easily cross-check the difficulties faced in terms of finance, in removing this error within and across the wind farm clusters.

c. Impact of error removal on techno-economic performance (IETP): Despite major technological improvements that have been achieved, the intermittent nature of wind power generation remains a hindrance in the adoption of technology for healthy operation of WTGs by both state utilities and private generators. This has implications on both technological and economic performance (technical performance and economic improvement). Though the removal of this inconvenience remains a long-term challenge for researchers and WTG manufacturers, its diminution can be brought about through a combination of technical, economic and institutional solutions.

d. Impact of error removal on socioeconomic benefits (IREB): This error is of importance in the situations like if there is a provision for rectifying the error by local people who will get benefit. By doing so, the society gets benefits in terms of economy. Different forms of compensations (including financial) can be offered to local authorities for the projects of local interest that cannot be implemented due to the wind power schemes. In addition, where interest exists, local authorities and citizens in the concerned area can be given priority for acquiring ownership rights in wind power plants. For improving the perception of environmental and sustainability advantages of wind energy, public education and awareness raising campaigns can be organized through the cooperation of local authorities, education institutions and non-governmental organizations (NGOs) for sustainable energy and the environment (European Energy Conference 1999).

\section{Formulation of questionnaires for data collection}

Data collection was executed with a structured questionnaire with participation from different stake holders working in wind industry at the capacity of "Service Head," Operation \& Maintenance engineers, shift engineers, condition monitoring system engineers, WET developers, Researchers, etc. During the preparation of questionnaire, the data used to identify errors and criteria are mainly obtained through an overall review of existing literature, country-specific reports and discussions with experts in the field. Then, opinions and value judgments for ranking were obtained from the various stake holders of WET.

The questionnaire designed for the study recognized critical dimensions under each error group to facilitate 
ranking by experts. For more convenient opinion collection process, the pairwise comparison matrix was used. Values were measured on a 1-9 scale to facilitate pairwise comparisons of five barrier groups with respect to each of the four criteria, and further four criteria with respect to the goal, as required by AHP. Enough care was exercised to avoid any bias. A total of 15 persons participated in the interview. Interviewees were identified from the core of the WET community, research/academic experts (Mahesh and Roopesh 2013).

The present study selected five major wind potential sites with different geographical locations, viz. Tamil Nadu, Gujarat, Rajasthan, Maharashtra and Karnataka. Selection of these locations is based on their contributions made toward the cumulative growth and percentage share of wind energy across India. Tamil Nadu is the leading state with a share of $37.59 \%$ followed by Gujarat, Maharashtra, Rajasthan and Karnataka with 16.66, 15.86, 14.09 and $11.21 \%$ respectively.

The main objective of this study is to prioritize the five error groups based on all the four important criteria using the AHP. However, an initial ranking of all the five error groups under each of the four individual criterions was carried out, but it only underscored the need for multi-criteria approach since different ranking errors were obtained under different criteria. Thus, it is reinforced that the error groups are to be prioritized by considering the effect of all the influencing factors simultaneously for fruitful results. It is for this reason that a MCDM tool like the AHP is adopted in this study.

\section{Results and discussion}

The AHP method is based on computing the weights of criteria (level 2) and alternatives (level 3) with respect to the level just above their own level (Fig. 1). Thus, criterion weights (priority) are calculated with respect to the goal, and barrier weights are computed with respect to each of the criterion. Table 1 gives pairwise comparison of the four criteria with respect to the goal in the selected five Indian wind farm sites.

The values in the table represent the pairwise comparisons for the wind farm and are obtained by computing geometric mean of all the individual pairwise comparisons of responses from 15 stake holders. By dividing each matrix element by the sum of respective column elements (normalization of column) and then by calculating the mean of each row, the priority is obtained. Table 2 shows that the stake holders give maximum priority (50\%) to IETP followed by IREB ( $25 \%)$. It is reasonable that stake holders put improvement in the overall techno-economic performance of wind farm much ahead of all others. Low weight of IETP disclosed that the stake holders did not give much importance to impact of error removal on
Table 1 Pairwise comparison of criteria with respect to the goal

\begin{tabular}{llllll}
\hline Criterion & IETP & FDER & IETP & IREB & Priority \\
\hline IETP & 1 & 0.82 & 0.16 & 0.32 & 0.09 \\
FDER & 1.21 & 1 & 0.67 & 0.31 & 0.16 \\
IETP & 6.07 & 1.50 & 1 & 5.26 & 0.50 \\
IREB & 3.07 & 3.21 & 0.19 & 1 & 0.25 \\
\hline
\end{tabular}

adoption of technology, as they are more interested in improving the performance rather than adoption a new technology. In the next step, the relative weights for each barrier groups (level 3) under each of the four criteria were obtained. For this purpose, pairwise comparison of five barrier groups with respect to each of the four criteria is performed, and the results are presented in Table 2. Similar to the previous step, normalization of the column followed by computation of arithmetic mean of each row gives the respective weights of the errors under a particular criterion. Subsequently, the composite weight for each barrier group was obtained by aggregating the weights through the hierarchy. The weight under each criterion, the priority of the criterion and the computation of composite weight of each error group are represented in Table 2.

OSFE is ranked first followed by TMFE, RSRE, DBTE and FGSE in that order for the selected five wind farms. It is clearly established that overspeed sensor failure error (OSFE) is the single largest error group largely affecting the healthy operation of WTGs in the wind farms. There are multiple reasons for this top-ranking position to OSFE error group in the wind clusters; for example, variation of wind velocity affects the speed of both wind turbine and generator which affects the operation of turbines.

\section{Conclusions}

In general, evaluating energy systems is a complex analysis that can be defined as a multi-dimensional space of different indicators and objectives. The use of multicriteria decision analysis (MCDA) techniques provides a reliable methodology to rank the relevant errors of the WTGs installed in the Indian context. Increased harnessing of wind energy assumes significance in this backdrop. However, implemented WTGs in any wind farm are confronted with several errors and hence require an appropriate prioritization for tackling them effectively. The current study ranked the errors that prevent the healthy operation of WTGs in the selected wind farms using a MCDM model adopting the perception and value judgment of different stake holders. Five pertinent error groups were considered, and their dimensions 
Table 2 Pairwise comparison of errors with respect to each criterion in wind farm cluster

\begin{tabular}{|c|c|c|c|c|c|c|}
\hline Error group & OSFE & TMFE & RSRE & DBTE & FGSE & Weight \\
\hline \multicolumn{7}{|c|}{ Impact of error removal on adoption of technology (IETP) } \\
\hline OSFE & 1 & 1 & 1.17 & 2.22 & 5.88 & 0.300 \\
\hline TMFE & 1 & 1 & 0.74 & 0.65 & 1.03 & 0.170 \\
\hline RSRE & 0.85 & 1.35 & 1 & 4.00 & 3.57 & 0.300 \\
\hline DBTE & 0.45 & 1.52 & 0.25 & 1 & 0.78 & 0.127 \\
\hline FGSE & 0.17 & 0.97 & 0.28 & 1.28 & 1 & 0.103 \\
\hline \multicolumn{7}{|c|}{ Financial difficulty in error removal (FDER) } \\
\hline OSFE & 1 & 4 & 5.88 & 7.14 & 833 & 0.550 \\
\hline TMFE & 0.25 & 1 & 2.22 & 1.28 & 5.56 & 0.170 \\
\hline RSRE & 0.17 & 0.45 & 1 & 1.53 & 7.14 & 0.130 \\
\hline DBTE & 0.14 & 0.78 & 0.65 & 1 & 7.69 & 0.120 \\
\hline FGSE & 0.12 & 0.18 & 0.14 & 0.13 & 1 & 0.030 \\
\hline \multicolumn{7}{|c|}{ Impact of error removal on techno-economic performance (IETP) } \\
\hline OSFE & 1 & 3.84 & 1.92 & 0.99 & 3.84 & 0.340 \\
\hline TMFE & 0.26 & 1 & 2.94 & 1.00 & 5.55 & 0.240 \\
\hline RSRE & 0.52 & 0.34 & 1 & 0.67 & 1.92 & 0.130 \\
\hline DBTE & 1.01 & 1.00 & 1.48 & 1 & 3.12 & 0.230 \\
\hline FGSE & 0.26 & 0.18 & 0.52 & 0.32 & 1 & 0.060 \\
\hline \multicolumn{7}{|c|}{ Impact of error removal on socioeconomic benefits (IREB) } \\
\hline OSFE & 1 & 6.25 & 5.88 & 1.19 & 5.88 & 0.440 \\
\hline TMFE & 0.16 & 1 & 1.69 & 0.84 & 6.66 & 0.160 \\
\hline RSRE & 0.17 & 0.59 & 1 & 0.52 & 5.26 & 0.120 \\
\hline DBTE & 0.84 & 1.19 & 1.89 & 1 & 7.14 & 0.240 \\
\hline FGSE & 0.17 & 0.15 & 0.19 & 0.14 & 1 & 0.040 \\
\hline \multicolumn{7}{|c|}{ Composite weight of the errors } \\
\hline Error group & TETP & ER & & TREB & Composite weight & Rank \\
\hline OSFE & \multicolumn{4}{|c|}{$(030)(0.09)+(055)(0.16)+(034)(050)+(0.44)(025)$} & 0.40 & 1 \\
\hline TMFE & \multicolumn{4}{|c|}{$(0.17)(0.09)+(0.17)(0.16)+(024)(050)+(0.16)(025)$} & 0.20 & 3 \\
\hline RSRE & \multicolumn{4}{|c|}{$(030)(0.09)+(0.13)(0.16)+(0.13)(050)+(0.12)(025)$} & 0.14 & 4 \\
\hline DBTE & \multicolumn{4}{|c|}{$(0.13)(0.09)+0.12)(0.16)+(0.23)(050)+(0.24)(025)$} & 0.21 & 2 \\
\hline FGSE & \multicolumn{4}{|c|}{$(0.10)(0.09)+(0.03)(0.16)+(0.06)(0.50)+(0.04)(0.25)$} & 0.05 & 5 \\
\hline
\end{tabular}

are identified before ranking them based on four criteria under AHP framework. Though all the considered errors were found significant, OSFE was found to be the most important one to be addressed in order to effectively operate the WTGs which have been installed in the selected wind farm clusters.

\section{Authors' contributions}

DGR carried out the formulation of problem related to the study. He has prepared the details of researcher structured administered questionnaires that help to get the necessary feedback from various stake holders related to wind industries as well as government organizations that support implementation of wind energy technologies. He has also carried out the multi-criteria analysis using well-known tool called analytic hierarchy process (AHP) to prioritize the various errors with pairwise comparison and rank them according to the analysis result. MGM has helped and participated in the interview conducted for various stake holders. His work is to approach various stake holders and assemble them either at one place or at multiple places. He used to carry out a set of questionnaires, explain the importance of each parameter (in view of investors and wind turbine manufacturers) regarding the questionnaires and get the required data that have helped to our study to carry out the AHP analysis. Both authors read and approved the final manuscript.

\section{Author details}

${ }^{1}$ Department of Mechanical Engineering, GM Institute of Technology, P.B. Road, Davangere, Karnataka 577006, India. ${ }^{2}$ Health Safety and Environment, Gamesa Wind Turbines Pvt. Ltd., Chennai, India.

\section{Competing interests}

We are presenting this paper purely in view of academic fulfillment and as part of our research work. There is no contact with either any of the organizations or people to support this research work in terms of financial or non-financial commitments. We have collected all the related data to the study only through field visits. Hence, the authors declare that they have no competing interests related to this work in fulfilling the required data.

Received: 22 September 2015 Accepted: 18 February 2016

Published online: 16 March 2016 


\section{References}

Antoniadou, I., Dervilis, N., Papatheou1, E., Maguire, A. E. \& Worden, K. (2015). Aspects of structural health and condition monitoring of offshore wind turbines. Philosophical Transactions, Royal Society Publishing, pp. 1-14. http://rsta.royalsociety.publishing.org/

Crabtree, C. J. (2010). Survey of commercially available condition monitoring systems for wind turbines. Super Gen Wind, November 2010.

Du, Z., Chen, X., Zhang, H., \& Yan, R. (2015). Sparse feature identification based on union of redundant dictionary for wind turbine gearbox fault diagnosis. IEEE Transactions on Industrial Electronics, 62(10), 6594-6605.

EERE 2030 (Energy Efficiency \& Renewable Energy 2030). Wind Energy of $20 \%$ by 2030: Increasing Wind Energy's Contribution to U.S. Electricity Supply'. http://www.eere.energy.gov/windandhydro/wind_2030.html. Wind programme to promote national security, U.S. Department of Energy. Also http://www.energy.gov/eere/renewables/wind. Accessed on March $12,2014$.

Fleming, P. (2011). Use Of SCADA data for failure detection in wind turbines. In Proceedings of 2011 energy sustainability conference and fuel cell conference, August 7-10, Washington DC, USA.

Forman, E. H. (1990). Facts and fictions about the analytic hierarchy process. In T. L. Saaty (Ed.), Multicriteria decision making. Pittsburgh: RWS Publications.

Gerber, T., Martin, N., \& Mailhes, C. (2015). Time-frequency tracking of spectral structures estimated by a data-driven method. IEEE Transactions on Industrial Electronics, 62(10), 6616-6626.

Hahn, B., Durstewitz, M., Rohring, K. Experience of 15 years with 1500 WTs. Institute for Solar Energy Technology (ISET), Germany, Information. http://renknownet2.iwes.fraunhofer.de/pages/wind_energy/data/200602-09Reliability.pdf

Lin, Y., Le, T., \& Liu, H. (2016). Fault analysis of wind turbines in China. Journal of Renewable and Sustainable Energy Reviews, 55, 482-490.

Long, H., Wang, L., Zhang, Z., Song, Z., \& Xu, J. (2015). Data-driven wind turbine power generation performance monitoring. IEEE Transactions on Industrial Electronics, 62(10), 6627-6635.

Mahesh, A., \& Roopesh, M. (2013). Personal discussion with resource persons from wind industry held in the months of October to December 2013

Ming, A. B., Zhang, W., Qin, Z.Y., \& Chu, F. L. (2015). Dual-impulse response model for the acoustic emission produced by a spall and the size evaluation in rolling element bearings. IEEE Transactions on Industrial Electronics, 62(10), 6606-6615.

Musial, W., Butterfield, S., McNiff, B. (2007). Improving wind turbine gearbox reliability. In 2007 European wind energy conference. http://www.nrel. gov/wind/pdfs/41548.pdf
Papatheou, E., Dervilis, N., Maguire, A. E., Antoniadou, I., \& Worden, K. (2015a). A Performance monitoring approach for the novel Lillgrund offshore wind farm. IEEE Transactions on Industrial Electronics, 62(10), 6636-6644.

Papatheou, E., Dervilis, N., Maguire, A. E., Antoniadou, I., \& Worden, K. (2015b). A performance monitoring approach for the novel Lillgrund offshore wind farm. IEEE Transactions on Industrial Electronics, 62(10), 6636-6644.

Paper presented and discussed at the European Energy Conference, under the theme of "Technological Progress and Energy Challenge", 30 September-1 October 1999, Paris.

Renewable Energy Policy Network for 21 st Century (REN21), Renewable (2010). Renewables Global Status Report, 2009 Update.

Saaty, T. L. (1996). The analytic hierarchy process. McGraw Hill: Reprinted By Rws Publications, Pittsburgh.

Sheng, S., Oyague, F., \& Butterfield, S. (2009). Investigation of Various Wind Turbine Condition Monitoring Techniques, 7th International Workshop on Structural Health Monitoring. Stanford: Stanford University.

Wiggelinkhuizen, E., Verbruggen, T., Braam, H., Rademakers, L., Xiang, J., \& Watson, S. (2008). Assessment of condition monitoring techniques for offshore wind farms. Journal of Solar Energy Engineering, 130, 031004

Yang, W., Court, R., \& Jiang, J. (2013). Wind turbine condition monitoring by the approach of SCADA data analysis. Renewable Energy, 53, 365-376.

Yang, W., Lang, Z., \& Tian, W. (2015a). Condition monitoring and damage location of wind turbine blades by frequency response transmissibility analysis. IEEE Transactions on Industrial Electronics, 62(10), 6558-6564.

Yang, W., Tavner, P. J., \& Tian, W. (2015b). Wind turbine condition monitoring based on an improved spline-kernelled Chirplet transform. IEEE Transactions on Industrial Electronics, 62(10), 6565-6574.

Yoon, J., He, D., \& Van Hecke, B. (2015). On the use of a single piezoelectric strain sensor for wind turbine planetary gearbox fault diagnosis. IEEE Transactions on Industrial Electronics, 62(10), 6585-6593.

Zaher, A., McArthur, S. D. J., Infield, D. G., \& Patel, Y. (2009). Online wind turbine fault detection through automated SCADA data analysis. Wind Energy, published online in Wiley Interscience (www.inderscience.wiley.com). doi:10.1002/we.319.

Zhou, D., Blaabjerg, F., Franke, T., Tonnes, M., \& Lau, M. (2015). Comparison of wind power inverters reliability with low-speed and medium-speed permanent-magnet synchronous generators. IEEE Transactions on Industrial Electronics, 62(10), 6575-6584.

\section{Submit your manuscript to a SpringerOpen ${ }^{\circ}$ journal and benefit from:}

- Convenient online submission

- Rigorous peer review

- Immediate publication on acceptance

- Open access: articles freely available online

- High visibility within the field

- Retaining the copyright to your article

Submit your next manuscript at $\boldsymbol{\wedge}$ springeropen.com 